\title{
Smart Irrigation System Using GPRS and Moisture Sensor
}

\author{
Srirang Desai, Undergraduate, University Of Pune, Pune, desaisrirang@gmail.com \\ Shrikrushna Aware, Undergraduate, University Of Pune, Pune, shriaware19@gmail.com \\ Shubham Dhamale, Undergraduate, University Of Pune, Pune, dhamaleshubham7@gmail.com
}

\begin{abstract}
With the advent of globalization, urbanization and modernization, water degradation has become an major concern today. Farming in India is still done as per traditional method that requires plenty of usage of water. Drip system has resolved this issue to some extent. But this system has suffered with overhead of continuous parameter checking and manual control. This paper focuses on designing of a smart drip irrigation system that comprises of sensing the moisture of soil which automatically controls switching of pump and valve with low consumption of available power. Automatic sensing of parameters remotely controls the drip valves of system. User friendly interface allows irrigation control with ease and less efforts. The moisture sensor will continuously sense the moisture content in the soil. The temperature sensor continuously monitors the temperature and if it is above threshold value then spraying system will turn on which will reduce crop temperature.
\end{abstract}

Index Terms - Drip system, sensing of parameters, automatic control, remote control, temperature sensor, threshold value, spraying system.

\section{INTRODUCTION}

In today's world the water scarcity is increasing day by day and demand for water is also increased as population is also increased. Agriculture is the backbone of our country. Traditional methods used by farmers require plenty of water for irrigation of crops. Drip system being very effective in reducing water requirement got popularity. Drip system basically comprises of flexible pipes having drips in between, valves to control water flow and water pump to pump water into pipes. Though this system is effective it has overhead of controlling valves manually. Also proper scheduling of irrigation is critical for efficient water management in crop production, particularly under conditions of water scarcity. The effects of the applied amount of irrigation water, irrigation frequency and water use are particularly important. Our designed system focuses on automatic and remote controlling of those valves by sensing parameters like moisture in soil and temperature. Also special feature of fertilizing crop remotely has added advantage to it. Simple and user friendly interface provides ease of handling the process.

\section{IMPORTANCE OF IRRIGATION}

Monsoon plays important role in irrigation. But inconsistent monsoon gave rise to different irrigation methods. Nowadays irrigation is one of the basic processes in farming. This process ensures the regular watering of the crop for the generation of food content in them. There are different methods for accomplishing this process. The method used depends on the parameters like type of crop, availability of water and traditional approaches. Below mentioned methods are commonly used by farmers

\section{METHODS OF IRRIGATION}

- Channel Irrigation

- Sprinkler Irrigation

- Drip Irrigation

- Surface Irrigation

\section{LITERATURE SURVEY}

The water requirements in irrigation being large, there is a need for a smart irrigation system that can save about $80 \%$ of the water. This prototype aims at saving time and avoiding problems like constant vigilance. It also helps in water conservation by automatically providing water to the plants/gardens depending on their water requirements. It is achieved by installing sensors in the field to monitor the soil temperature and soil moisture which transmits the data to the microcontroller for estimation of water demands of plants.

The greenhouse based modern agriculture industries are the recent requirement in every part of agriculture in India. In this technology, the humidity and temperature of plants are precisely controlled Due to the variable atmospheric circumstances these conditions sometimes may vary from place to place in large farmhouse, which makes very difficult to maintain the uniformity at all the places in the farmhouse manually. The green house based modern agriculture industries are the recent requirement in every 
part of agriculture in India. In this technology, the humidity and temperature of plants are precisely controlled. Due to the variable atmospheric conditions sometimes may vary from place to place in large farmhouse, which makes very difficult to maintain the uniformity at all the places in the farmhouse manually. For this GSM is used to report the detailed about irrigation. The report from the GSM is send through the android mobile.

The some system highlights the development of temperature and soil moisture sensor that can be placed on suitable locations on field for monitoring of temperature and moisture of soil, the two parameters to which the crops are susceptible. The sensing system is based on a feedback control mechanism with a centralized control unit which regulates the flow of water on to the field in the real time based on the instantaneous temperature and moisture values.

\section{LITERATURE REVIEW}

Traditional irrigation methods being water inefficient gave rise to various researches which are presented in recent decades for efficient and automatic irrigation systems.

Remote switching of water pump made the different irrigation systems somewhat automatic

[1]. GSM is a basic wireless communication medium which is also cost effective. Using Short message service of GSM remote control of irrigation is possible

[2]. Mobile being portable and user friendly device and also due to inbuilt GSM and GPRS facility got popularity and used in many such automated irrigation systems

[3] Sensing of different parameters in the farm field such as temperature, soil moisture and using them in designing the efficient irrigation system is possible. For sensing of parameters different sensors can be used such as semiconductor temperature sensor and soil moisture sensor [4]. Use of water level indicator for sensing amount of water in the tank is essential in designing any irrigation system as whole system is designed for provision of water

[6]. Finally the cost of any designed system plays important role in its manufacturing, usage and market reliability. Designing of system in optimum price is also important on the remote control of water motor and drip valves. For this purpose different communication media such as GSM, GPRS, Wi-Fi are used. Also processing elements used are different microcontrollers, IoT, Arduino. Also several papers focus on sensing of parameters in field and using them in designing the irrigation system.

\section{PROPOSED SYSTEM}

\section{PROJECT DESIGN FLOW}

It consists of a microcontroller PIC16F877A which is the brain of system. Both the moisture and temperature sensors are connected to the input of the controller. There are 3 moisture sensors \& 1 temperature sensor is used in the system.

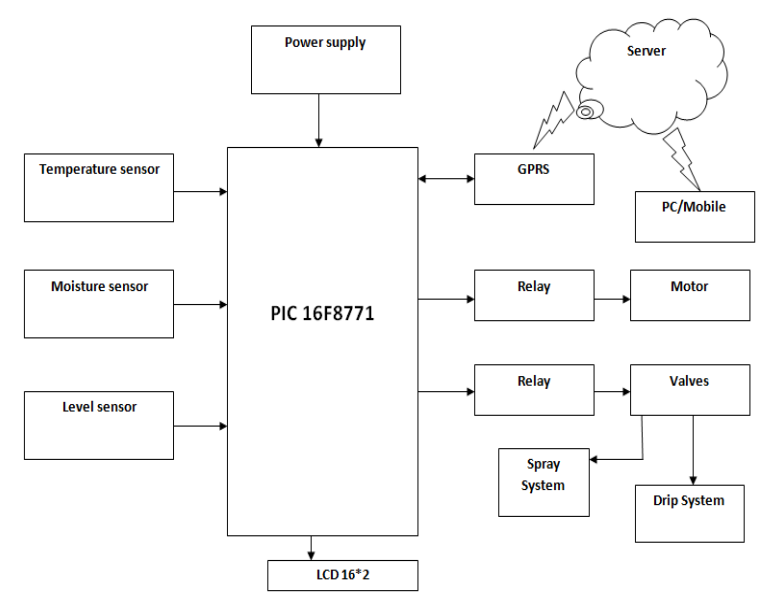

Fig.1 Functional Block Diagram of Smart Irrigation System

Temperature sensor output is provided to ADC of the microcontroller. The moisture sensors provide the digital output according to set threshold. Level indicator is also used to indicate the level of water for managing the water level. Solenoid valves as well as water pump and fertilizer pump are connected to microcontroller through relays. GPRS module is connected through serial interface to microcontroller.

\section{HARDWARE COMPONENTS}

Following is the list of components used in the hardware build.

1. Temperature sensor

(LM35)

2. Microcontroller

(PIC16F877)

3. Soil moisture sensor

(Kits guru)

4. SIM 900 GPRS Module

5. Solenoid valves

(E-70)

\section{USER INTERFACE OF SYSTEM}

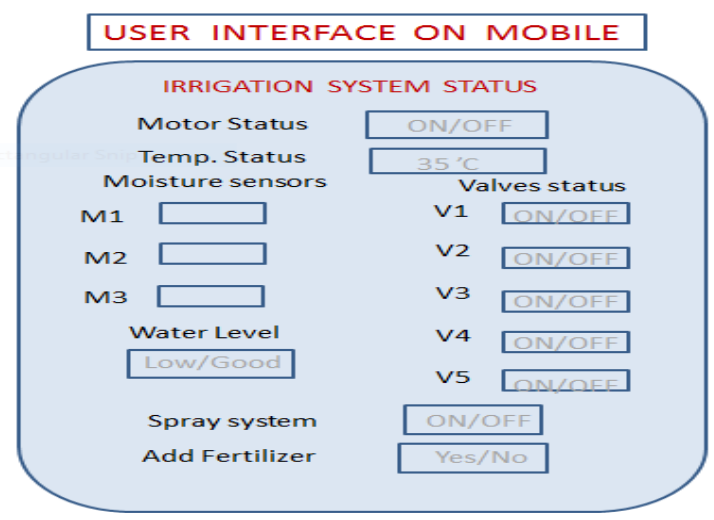

Fig 2 .User Interface of page for Smart Irrigation System 
The sensed parameters are moisture level, temperature, motor (water pump) status, spray system and the valves' status display on the user interface. The user interface is made using web page \& GPRS helps to provide it to user. Special option of fertilization is also provided in the interface.

\section{SYSTEM ARCHITECTURE}

\section{METHODOLOGY}

The proposed system basically consists of water tank, fertilizer tank, drip system, solenoid valves, spraying system, moisture sensors, temperature sensor, etc. The water tank and fertilizer tank are connected to drip system using pipes. The field is divided into different sections according to coverage area of drip system. This drip system consists of solenoid valves and drips. Dedicated pipeline is provided for the spraying system. Each section of field has separate soil moisture sensor. For whole field a single temperature sensor is provided which is enough. A submersible water pump is used to pump water into drip system. The water tank is also provided with the level sensor to sense the water level in the tank.

Moisture sensors from respective sections sense the moisture from soil and gives information to user through user interface. According to information, the valves are controlled. For reducing effects of adverse climatic changes like sudden rise in temperature, the spraying system is provided which will spray the water on crop to reduce its temperature. For fertilization process a fertilizer tank with pump is provided. It pumps the liquid fertilizer directly to the drip system so that by combining with water, fertilization can be achieved. All the sensed parameters, status of valves, water pump and water tank level as well as spray system status information will be sent to user using the GPRS. Besides that the information could be also stored in cloud for detailed analysis and a time period can be set based on every season.

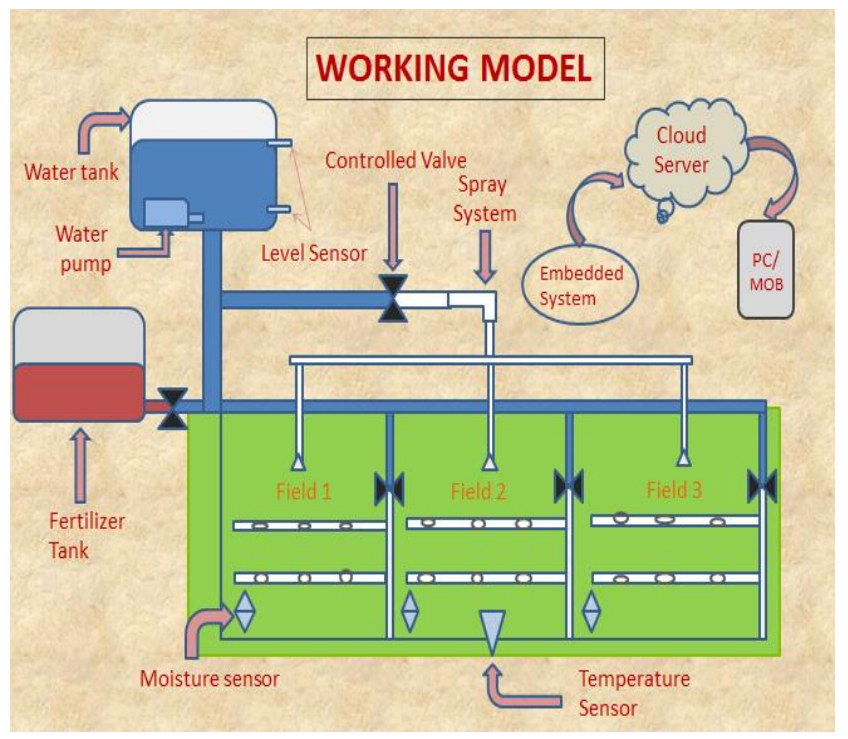

Fig.3. Working Model of system

\section{ALGORITHM}

Brief system algorithm: The system algorithm explains the flow of the system.

\section{Start}

2. If system detects the moisture then

3. It will check whether the temperature $>35 \mathrm{C}$ then

4. Spray system will turn on for some time.

5. If it does not detects moisture then

6. It will check whether the block 1 or block 2 detect

7. If block 2 is detect then

System will turn on valve 2 and Motor 2 will turn on.

8. If block 1 is detect then..

System will turn on valve 1 and Motor 1 will turn on.

9. Level sensor will check the level of water in the tank.

10. If tank is empty,

11. It will turn on valve 3 for some time and then turn

off valve 3 .

12. If user wants to provide fertilizer then the user will communicate through GPRS to turn on fertilizer tank.

\section{RESULTS \& DISCUSSIONS}

The proposed system works in different stages and conditions. The various conditions are derived from temperature and soil moisture considerations. The different derived conditions for the system are mentioned below.

\section{Simulation RESULTS}

1. In this simulation Temperature is 35 degree $C$ and Water tank level indication is healthy

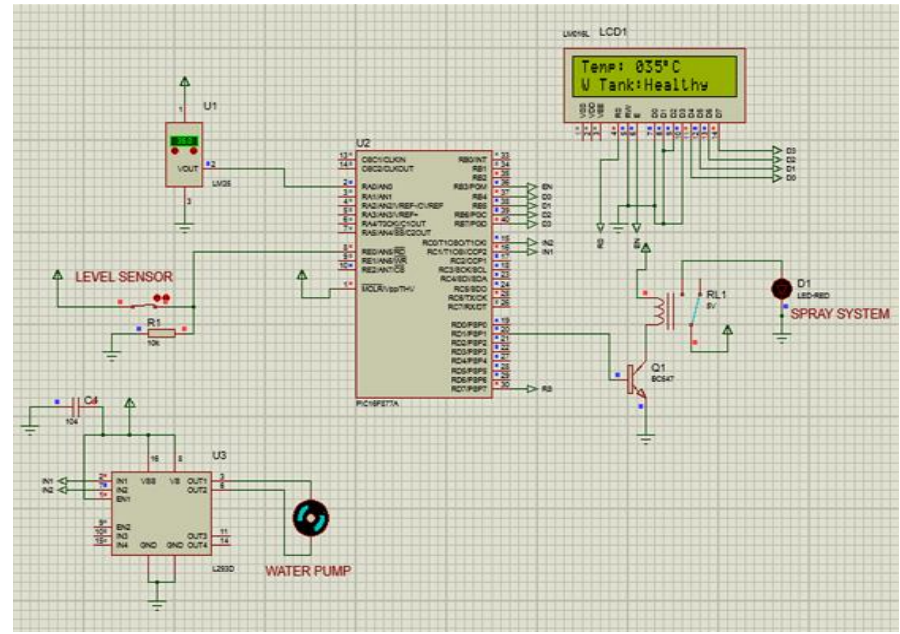

Fig.4. Simulation Result 1

In the simulation diagram above the LCD display shows the water tank level which it shows healthy and current temperature of the field 35C.Level sensor is used to 
detect the level of water tank. As the sensed temperature is below the threshold set of $37 \mathrm{C}$, the spray system is idle

2. In this simulation Temperature is 35 degree $\mathrm{C}$ and Water tank level indication is low

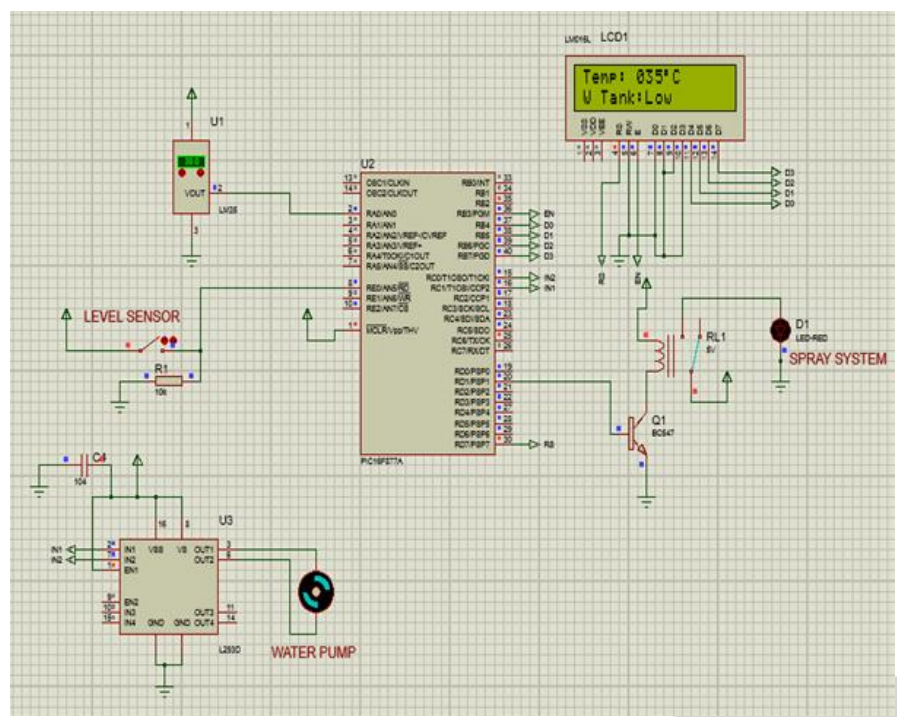

Fig.5. Simulation Result 2

In the above simulation diagram the temperature is remained same as 35C; But water tank level is low as shown in the LCD. Here also as temperature is below the threshold set, the spray system is off.

3. In this simulation Temperature is 38 degree $\mathrm{C}$ and Water tank level indication is healthy.

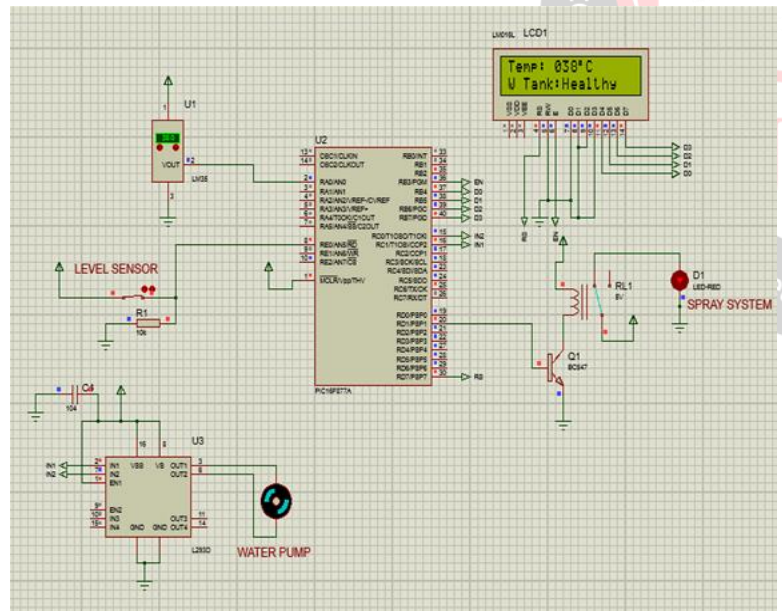

Fig.6. Simulation Result 3

In simulation shown above the temperature shown is $38 \mathrm{C}$ which is above the threshold set of $37 \mathrm{C}$. Also the water tank level is healthy. As the temperature is above the threshold set and water tank level is also healthy, the spray system becomes active which is shown by glowing of red led

4. In this simulation Temperature is 38 degree $\mathrm{C}$ and Water tank level indication is low.

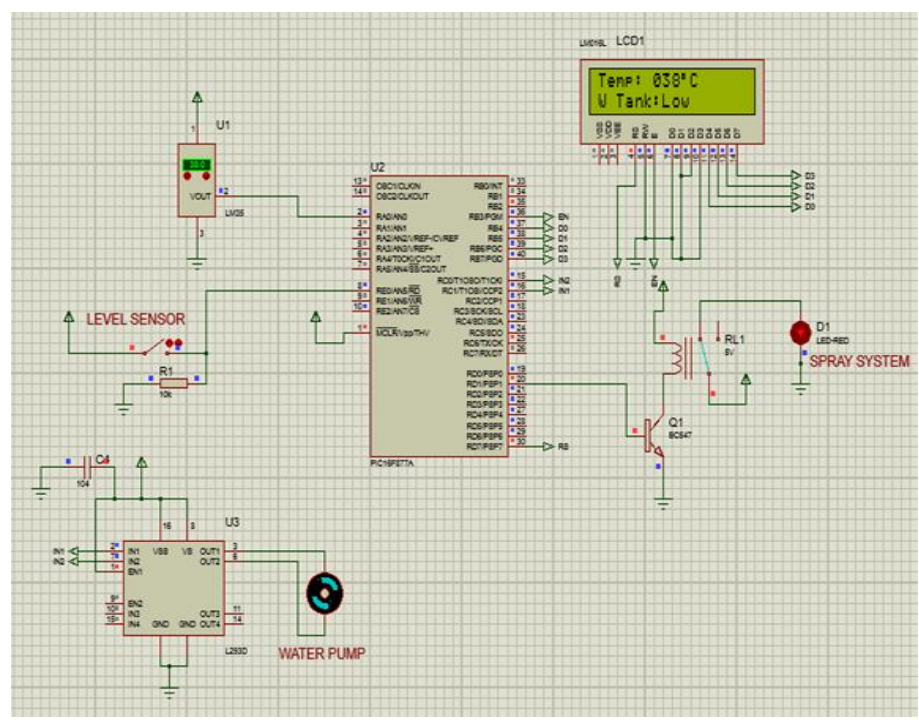

Fig.7. Simulation Result 4

In simulation shown above the temperature shown is $38 \mathrm{C}$ which is above the threshold set of $37 \mathrm{C}$. Also the water tank level is low. As the temperature is above the threshold set but water tank level is low, the spray system remains in off state

HARDWARE RESUlTS :

Case 1 [Normal Temperature (20 to 37 degree cel)] :

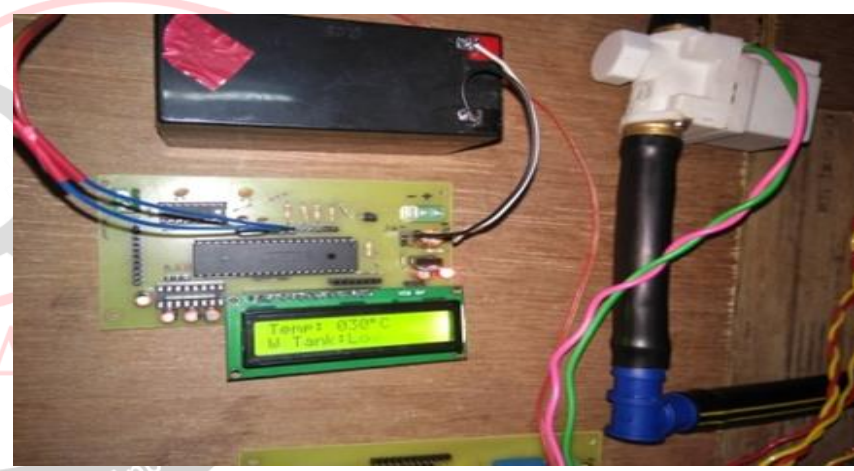

Fig.8. Normal Temperature

This is the normal condition in the field. Temperature of the field is less than the threshold set i.e. temperature is normal. In this case the crop temperature will be normal and therefore the spray system will be dormant.

Case 2 [High Temperature (more than 37 Degree Celsius)] :

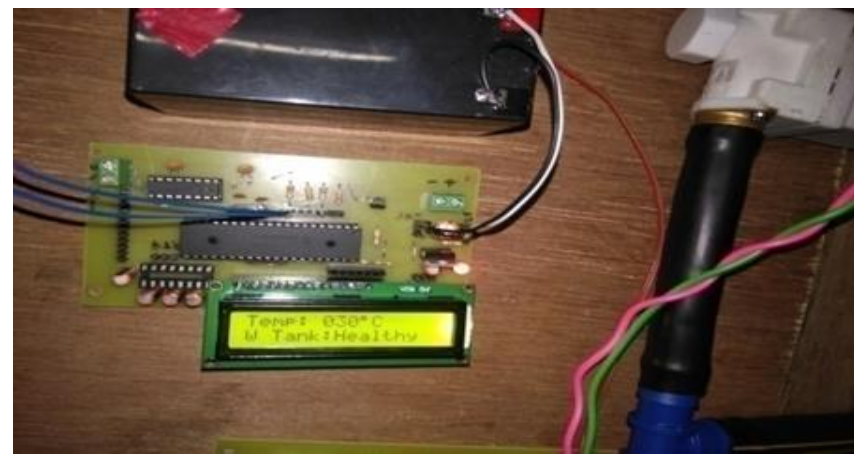

Fig.9. High Temperature 
This condition will occur in adverse climatic conditions. Temperature of the field will raise high and so of the crop. The temperature will exceed the threshold set and so the spray system will start. Before starting the spray system, the system will check the water level of the water tank. If the water level of the tank is healthy, the spray system will get activated. But if the water level in tank is poor or low, the spray system won't get start.

Spray system is especially designed for the adverse climatic condition of temperature and it is designed such that it will be on for specific time interval and will be off for specific time interval. This will make the system stable and also will conserve the water in tank. The status of spray system is also shown to the user.

\section{Case 3 [Soil Moisture is low/absent] :}

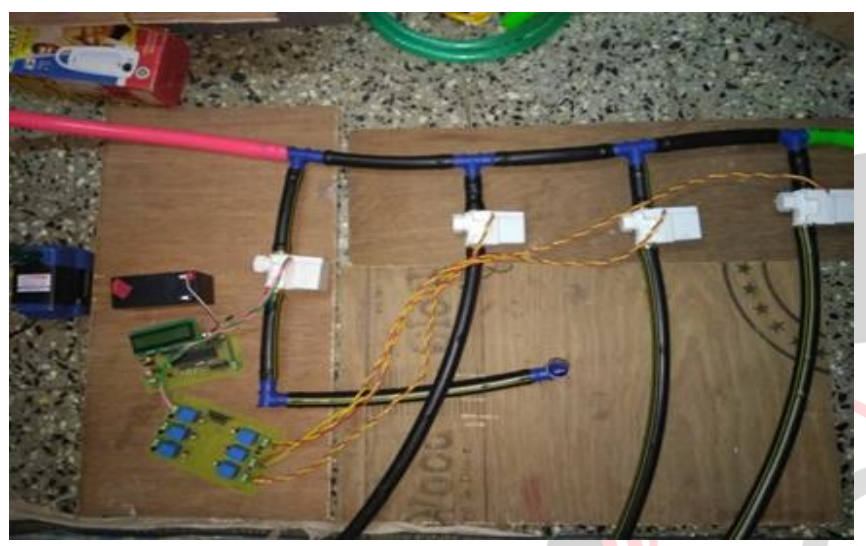

Fig.10. Drip System Overview

This condition is normal part of irrigation process. After specific time period, the moisture level in the soil will get lower down. This lowering depends on the type of soil, type of crop and also the time interval. By considering all these parameters, the threshold for moisture sensor output can be set. Different sections in the field will have different moisture sensors. In this soil moisture level from each section will get sensed and sent to user.Also valves in low soil moisture sections will get started. Before that the water level in the tank is checked. If condition is healthy then and then only the valves get open, otherwise they will be close.

These valves' status also will be shown to the user. The valves used are solenoid valves working on only two conditions on and off. Also moisture sensors used are digital in nature giving only two outputs.

\section{Case 4 [Soil Moisture is present] :}

This condition is also normal part of irrigation process. After sensing low moisture, as valves get open and so after certain time period moisture level of soil will get increase. After reaching a certain moisture level which is above the threshold set, the valves will get close. Also the water pump in tank will get off if it is not required by any other process.

\section{Case 5 [Fertilization Process] :}

This is the special option provided in the system. If a farmer wants to fertilize the crop he has to provide 'YES' response on the interface. After this the water pump will get off if it is on. Also water tank level will be checked. If both conditions get satisfy, the pump in the fertilization chemical tank will get on and will pump the liquid fertilizer to drip pipes. After finishing this, the water pump will get start and liquid fertilizer along with water will get dripped to crop.

Here again fertilization to specific section in the field is possible due to provision of different valves in different sections.

\section{APPLICATIONS}

1. In hydroponic system for cattle feed.

2. Used in home gardening system.

3. Used in remote fertilization system.

\section{Conclusion}

In the proposed system there are various benefits for the government and farmers. The automatic irrigation system optimizes the usage of water thereby reducing wastage and the human efforts. In the present era, the farmers use irrigation technique through the manual control, in which the farmers irrigate the land at regular intervals In dry areas where there is inadequate rainfall, irrigation becomes difficult. Hence we require an automatic system that will precisely monitor and control the water requirements in the field. Installing Smart irrigation system saves time and ensures judicious usage of water. This architecture uses microcontroller which promises an increase in system life by reducing power consumption.

We can control the flow of water by continuously monitoring the status of the soil and thereby reduce the wastage. Knowing the status of moisture and temperature through GSM with the use of moisture and temperature sensors, water flow can be controlled by just sending a message from our mobile. The design is low power, low cost, small size, robust and highly versatile. Thus, this system avoids over irrigation, under irrigation, top soil erosion and reduce the wastage of water.

\section{FUTURE SCOPE}

This system can be implemented in horticultural lands, parks, gardens, golf courses irrigated. Thus, this system is cheaper and efficient when compared to other type of automation system. In large scale applications, high sensitivity sensors can be implemented for large areas of agricultural lands. A stand by battery or solar cells can be implemented which will come into use in case of power cuts. A secondary pump can be used in case of failure of the pump. The special mobile application can be designed instead of a web page. 


\section{ACKNOWLEDGMENT}

This paper and the research behind it would not have been possible without the exceptional support of my supervisor Dr. Chanakya Kumar. Jha and Prof. P. V. Mulmule. Their enthusiasm, knowledge and exacting attention to detail have been an inspiration and kept my work on track from my first encounter with the motive to establish the development of Smart Village. Last I want to thank our college E\&TC Department Staff for providing Financial aid required for successful completion of our dream Project

\section{REFERENCES}

[1] S. Darshna, T.Sangavi, Sheena Mohan, A.Soundharya, Sukanya D, Smart Irrigation System.

[2] Pavithra D. S, M. S .Srinath, GSM based Automatic Irrigation Control System for Efficient Use of Resources and Crop Planning by Using an Android Mobile.

[3] Rohit Somvanshi, Akshay Suryawanshi, Rohit Toraskar, Smart Irrigation System Using Mobile Phone, International Research Journal of Engineering and Technology (IRJET), June 2016.

[4] Chandan kumar sahu, Pramitee Behera., A Low Cost Smart Irrigation Control System, IEEE SPONSORED 2ND INTERNATIONAL CONFERENCE ON ELECTRONICS AND COMMUNICATION SYSTEM (ICECS 2015).

[5] Dishay Kissoon , Hinouccha Deerpaul, Avinash Mungur, University of Mauritius, A Smart Irrigation and Monitoring System, International Journal of Computer application (0975-887) Volume 163 - No 8, April 2017.

[6] Babanna Kumbar, Basavaraj Galagi, Bheemashankar and Naveen Honnalli Bonfring, D.S. Smart Irrigation System Using Internet of Things, International Journal of Research in Communication Engineering, Vol. 6, Special Issue, November 2016.

[7] S.G.Manoj Guru , P.Naveen,R.Vinodh Raja, V.Srirenga Nachiyar, SMART IRRIGATION SYSTEM USING ARDUINO SSRG, International Journal of Electronics and Communication Engineering - (ICRTECITA-2017) - Special Issue - March 2017 ISSN : 2348 - 8549. www.internationaljournalssrg.org Page 182

[8] Apurva Tyagi, Nina Gupta, Smart irrigation System IJIRST -International Journal for Innovative Research in Science \&amp; Technology| Volume 3 | Issue 10 | March 2017. ISSN (online): 2349-6010.

[9] A.Salam Al-Ammri1, Sherin Ridah J,Smart Irrigation using Wireless Sensor Network, International Journal of Engineering Research \&amp; Technology (IJERT), Vol. 3 Issue 1 1, January $\quad-2014$

\section{IJERTV3IS10954.}

[10] Jai Vir Singh, Water requirement of different crops report in 'Agropedia', Submitted 27/01/2010.

[11] Rohini Mohan, Article in Economic Times "Is thriving sugarcane crop responsible for Maharashtra's Marasthwada and Vidarbha's water woes?", September 09,2015 .

[12] Dr. Amrit Patel, Irrigation in India-Focus on some serious issues, August 6,2013 .

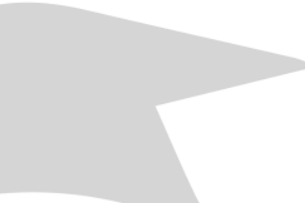

\section{(n)}

